\title{
On the Core Theory of Process Interactions and Cohesion as Its Integral Effect
}

\author{
Aristova Svetlana Mikhailovna ${ }^{1}$, Daradkeh Yousef Ibrahim ${ }^{2}$ and Korolev Petr Mikhailovich ${ }^{3 *}$ \\ ${ }^{1}$ Researcher, Kudymkar, Russia \\ ${ }^{2}$ Associate Professor of the College of Engineering at Wadi Addawasser, Saudi Arabia \\ ${ }^{3}$ Studia Korolevae Int, Volodarskogo, Russia \\ *Corresponding author: Korolev Petr Mikhailovich, Studia Korolevae Int., Kudymkar, Perm krai, 619000, Russia
}

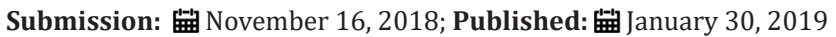

\begin{abstract}
The aim of the work is to develop the core theory of interaction of the processes, such as problematization, schematization, objectification, positioning. These processes are the constructs of the technology of organization and management of thought processes. As a focus, we chose what makes the group holistic and cohesive. Taking as a basis the experience of discussing these processes and their interactions, the authors develop two versions of the theory, introducing methods of combinatorics and discrete mathematics into the constructive field. The metric basis of the core theory of interaction leading to cohesion is constructed, hypotheses of symmetry of processes are put forward, laws of interaction are offered. In the article, research restrictions related to the enneadic metric are adopted, the method of analogy with the core theory of modern physics of Wilczek is used. An application is presented in the form of a game with representatives of the value categories that make up the corporate philosophy of Bio Informatics. The results of the article are of practical use in the development of the microbiology the proposed theory can be applied to the development of an optimal set of tools for gene ontology, taking such tools as AMIGO, OBO-EDIT as the analyzed material. Game simulation and modelling can also be improved by applying cohesion theory. An analysis of the quantitative understanding of the biological system, as well as the possibility of predicting systemic features that are the goal of system biology, and the field of its application, related to the consideration of nonlinearity, may also include a theory of cohesion. In pharmaceuticals and the development of drugs in terms of their effects on the body, the effect of cohesion is important. The architecture of the core theory is original, the theory is important for programming and controlling life processes.
\end{abstract}

Keywords: Cohesion; Laws of interactions; Mapping; Deepening; Thinking; Anticipating; Creating Alternatives; Core Theory

\section{Introduction}

In sociology the cohesion of a group or society is the result of the interaction of several important processes that determine the activity and life of the group. The concept of cohesion is used in the chemistry of intermolecular interactions, in computer science as a measure of harmonizing the common code with the code of modules, in the geology of rock movement, in linguistics as a set of elements that make the discourse semantically coherent in political science as the vital links between members of a group or society. Cohesion occurs when the links provide relationships between members of the group and the relationship to the group. Forsyth [1] notes that even though cohesion is a multi-grid process, it can be divided into four main components: social relations, working relations, achieved unity and emotionality. We view processes as the processes leading to cohesion, which have been paying close attention to during the last 64 years in the framework of the methodological program of the Moscow Methodological Circle (since 1954) and the Nonprofit Science Foundation "GP Shchedrovitsky Institute for Development" (since 1995) [Non-Profit Scientific Foundation]. In the national methodological school, in the course of its formation, the transition from modern to late modernism is reflected, as a certain frontier, which moves to the future in a non-destructive manner, to avoid falling into a postmodernist trap, when creating chaos to be controlled as an impersonal mass [2].

At schools on technologies of thinking, these processes (schematization, objectivization, positioning and problematization) are brought to the level of programs. One of the participants of such a school in 2015 on the topic of "schematization" Knyaginin [3] shares his impressions, in particular, he cites the moments from the installation report of Shchedrovitsky: "thinking organizes activities and brings organization into some reality, and schematization provides a selection of a complex of processes that ensure this organization, "highlighting" each time a key, basic process . The organization of thinking leads to the approval of one or another scheme as the principle of organization, in this sense (albeit with great exaggeration from me) the schemes are fixed, and in some cases, becoming part of the activities, create societies and communities, lie at the basis of mental and activity, professional (or similar to them) practices, for example, the same philosophical and methodological work. He asks whether it is interesting to know whether there is a main scheme, or whether it is a complex, and further explains: The schemes are important and fulfill the organizing role This is an expression of the principle 
of organization. Therefore, the scheme is close to the model. Scheme and schematization are a way of working with complexity: a set of elements, a multitude of links, a multitude of variants of changes Another participant in the school in Jurmala. Saakov [4] worked on the topic "Positional structures of the scheme of thought activity and management tasks" to make a presentation on the XXIII readings of the memory of GP Shchedrovitsky. "The concept of managerial thinking in the system-driven activity approach" [4] In this article, we consider a kind of "main" scheme, or the main theory, core theory (if we use the term Wilczek [5].

\section{The first version of the theory}

In one of the lectures (in Tomsk) Shchedrovitsky [6] on top of the scheme of thought activity (and this is in a certain sense the main scheme developed by MMK in the period of methodological practice in the motivational form in 1979-1992 of organizational and activity games in different practical regions) are drawn solid and dotted double arrows, which connect the "places" in which problematization occurs (between regions 3 and 5, closer to 3 where the text is formed), schematization (between regions 2 and 4), objectification (in region 6) and position action (in region 1 and 2 my sledey solvency layer) [7] . The dashed connection between positioning and problematization, positioning and objectification, and between schematization and problematization has - we dare to suggest a different interpretation than a connection depicted by a solid line between: problematization and objectification, objectification and schematization and schematization and positioning (Figure 1). There is a callout from the connection of positions: active 6 and reflexive 6-6: "thinking is played out as an effect of changing positions." Shchedrovitsky [8] suggests differing the scheme for thinking activity and the thinking activity (ThA) as it is. Scheme, on his regard, is an effect of the conception-focal schematization, when we study a complex phenomenon, and focusing on separate processes, we form the focal images one after another. Uncertain object gets the set of focal images of the processes and their corresponding structures. When we have designed the form to combine them, we get the scheme of the object. Not image of the object but a set of its projections.

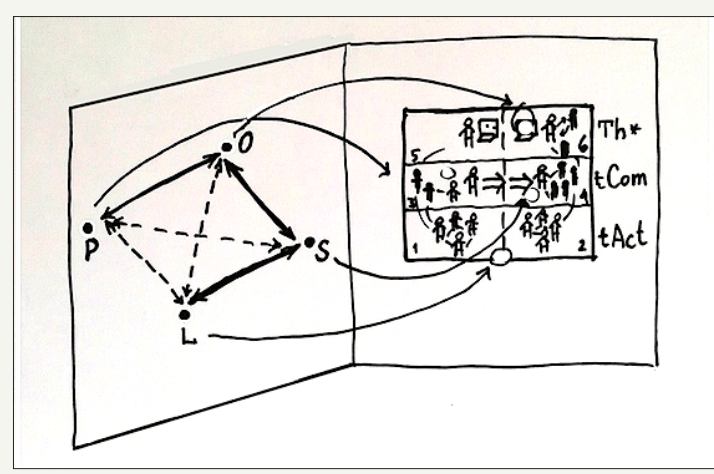

Figure 1: The main technologies of organization and management of thought processes (Schedrovitsky [6]) This is a slide reproduction from the lecture of Shchedrovitsky [8] in Tomsk.
Principle of multiple existence is stated with the scheme of ThA; we impose the anticipating cohesion on the set of images. The scheme of ThA has no cohesion, it is added by actor during realization; actor, from the definite position, draws the bonds on the scheme-principle, concept-focal scheme of ThA. In dimension of organization activity which supplement to ontology-object dimension, a set of position are designed. These positions are the base for the bond drawing beyond the field that defined with scheme of ThA in correspondence with tasks, frames and horizons of actors [8]. From the analytics of mono processes, the methodology moves to transfer laws of monopoieses to a poly process, to overcome frame of modelling and research [8]. Work on concept-focal organization, Shchedrovitsky [8] argues, is proportionate to history of Moscow methodology circle. It's actual the task to rewrite the scheme of ThA in conceptual focuses of separate stages of the circle [8].

\section{Development of ideas}

Obtained a lot of 8 connections on the sides and 4 links on the diagonals of the square, they are as follows:

$$
\begin{aligned}
& {\left[\left\{b_{i}\right\}\right] O P^{(4)}, P O^{(4)}, P L^{(4)}, L P^{(4)}, L S^{(4)}, S L^{(4)}} \\
& S O^{(4)}, O S^{(4)} ; P S^{(4)}, S P^{(4)}, O L^{(4)}, L O^{(4)}
\end{aligned}
$$

The movement from left to right according to the MD scheme puts forward the following sequence of processes in the case of such an orientation of the square:

[LtR] problematization $\rightarrow$ positioning $\rightarrow$ objectification $\rightarrow$ schematization

Movement from top to bottom from thinking to action:

$[\mathrm{TtA}]$ objectification $\rightarrow$ problematization $\rightarrow$ schematization $\rightarrow$ positioning

Movement from the bottom up from situations of activity to thinking:

[AtT] positioning $\rightarrow$ schematization $\rightarrow$ problematization $\rightarrow$ objectification

In the sequence [LtR], the meaning of such an order of the event series is hidden, which obeys the logic "before and after". This logic introduces one of the meanings of time in the modes of the past, the future and the present.

\section{Time and uncertainty}

Connections PO, PL, PS, OS, LS, LO specify the time flow channels in the conversion (PtF) conversion natural course of events. The links OP, LP, SP, SO, SL, OL define the corresponding timeflow channels in the conversion (FtP) current present in the past according to the future model. If we take the position of the abovementioned square as 30 degrees turned to the left, and eliminating one of the vertices, namely $L$, we reduce the set $\{b i\}$ to the set $\{b j\}$, the reduction $\{\mathrm{bi}\} \rightarrow\{\mathrm{bj}\}, 12 \mathrm{D} \rightarrow 6 \mathrm{D}$ : LO, OL They disappear or are drawn into the focus of objectification; LP, PL enter the vertex $\mathrm{P}$, and LS, SL - on the inside of the vertex S. The semantics of the PS and SP 
connections becomes complicated, as does the semantics of the OP, PO, OS, SO links.

$$
\text { The set }\{b j\}=\left\{b_{j}\right\}=\left\{O P^{(3)}, P O^{(3)}, O S^{(3)}, S O^{(3)}, P S^{(3)}, S P^{(3)}\right\}
$$

Inside the problematization process, it is not difficult to single out the proper elements, the elements of the PO (3), OP (3), PS (3), SP (3) links. Process sequences are also reduced,

[LtR] (3) problematization $\rightarrow[\mathrm{X}] \rightarrow$ objectification $\rightarrow$ schematization

[TtA] (3) objectification $\rightarrow$ problematization $\rightarrow$ schematization $\rightarrow[\mathrm{X}]$

[AtT] (3) [X] $\rightarrow$ schematization $\rightarrow$ problematization $\rightarrow$ objectification

Here we have a region introducing uncertainty (localization), which we denote by the letter X (Figure 2). It leads the process of problematization and from it emerges an arrow to the process of objectification; the object becomes the subject of schematization. Figure 2 Schematization as the object-subject transformation.

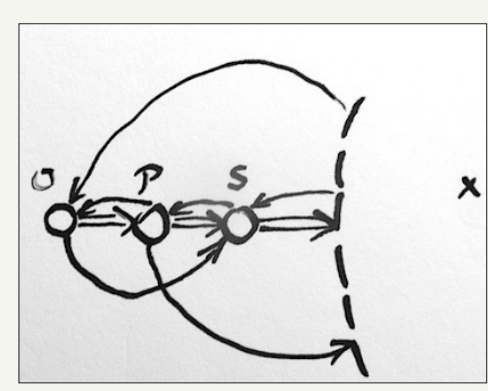

Figure 2: Schematization as the object-subject transformation.

\section{Reduction}

Two examples of reduction.

(1) when the cooperation of the processes of objectification, problematization and schematization (OPS system) as a certain complex becomes some sort of "explorer" of the region X, (2) when a number is included from the X-region, including the process of schematization, problematization and the process of objectification (SPO system). As a result of the reduction, we are forced to say that in addition to the $\mathrm{P}, \mathrm{O}, \mathrm{S}$ processes, the additional processes $\mathrm{P}_{\mathrm{x}^{\prime}}$ $\mathrm{O}_{x^{\prime}} \mathrm{S}_{\mathrm{x}^{\prime}}$ which have been induced by elimination of the positioning process, appeared and, accordingly, the imaginary domain $\mathrm{X}$ appeared, the parameters of which are related to the processes of problematization, objectification and schematization system): Xp, Xo, Xs. Restoration of the system of quadric bonding processes is possible when solving symbolic equations:

$$
\begin{aligned}
& P x+X p=P L 0 \\
& O x+X o=O L 0 \\
& S x+X s=S L 0
\end{aligned}
$$

where index 0 denotes the base level for constructing the relations PL, LP, OL, LO, SL, LS, respectively. The POS system is not "tied" to positioning if the L positioning process is eliminated (Figure 3).

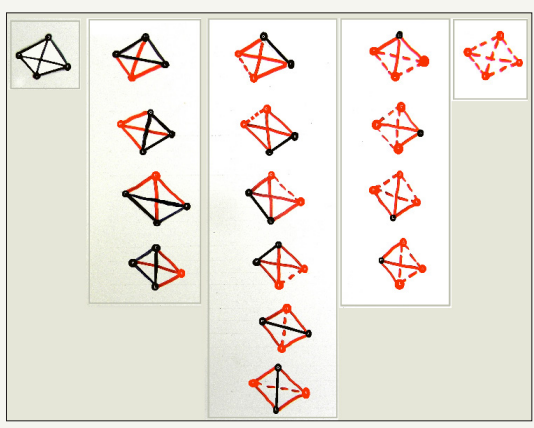

Figure 3: Between the two extreme situations - full certainty and complete uncertainty, there are 14 different situations of management and organization of MD processes, four each, when one process is defined or not, and six situations where two processes are not defined.

Similarly, if one of the four other vertices of the square are eliminated, the corresponding reduction is $12 \mathrm{D} \rightarrow 6 \mathrm{D}$. And an imaginary area is formed that induces additional processes. We can allow elimination of two, three, and even all processes, in this case we fall into the region of complete uncertainty, in which we can have only those unknowns that have no finite and boundary conditions. The launch of any workflow will be difficult and burdened by this multitude of unknowns, since for the reproduction of management and organization of thought processes, it is necessary to go from zero dimension to 12 dimensions: 0 -1-2-6-12.

\section{The second version of the theory}

We examined these processes on a different metric basis, on the enneadic structure [9]. At the same time, we make some sort of semantic transformation. Re-identified the processes as:

$$
\begin{gathered}
\text { schematization } \rightarrow \text { mapping } M \text {, } \\
\text { problematization } \rightarrow \text { deepening, } D, \\
\text { positioning } \rightarrow \text { anticipating, } A,
\end{gathered}
$$

objectification $\rightarrow$ creating alternatives, $L$.

Using the symmetry hypothesis, we added two more processes: thinking (Th), and teaming, Te. The last process can be called cohesion. Using the law of cyclicity inherent in the dynamics (kinematics) of the enneagram, namely the order of the passage of the

\section{M-L-A-Te-D-Th-M processes,}

we can infer the determination of processes in the first version of the theory (Figure 4):

$$
\mathrm{S} \rightarrow \mathrm{L}, \mathrm{L} \rightarrow \mathrm{A}, \mathrm{Te} \rightarrow \mathrm{D}, \mathrm{D} \rightarrow \mathrm{Th}, \mathrm{Th}-\mathrm{M}, \mathrm{A}-\mathrm{Te}
$$

The last two relations are determined by symmetry with respect to the triangle (triad): R (transforming) - M \& T (methods and tools) - P (Practice). 
Note that R (transformation, transformation, modernization) is determined by the relation

$$
R=T e+T h
$$

to the right-hand side of which, by virtue of the symmetry hypothesis, we would add two more terms, in this case we obtain the following law of the definition of modernity: Figure 4 Or, following the ironic remark of F. Vilczek [10] on the method of teaching physics at accelerated courses (three Ohm's laws), for cohesion we obtain a relation that determines the basic position of the general theory of cohesion:

$$
T e=R-M-T h-A
$$

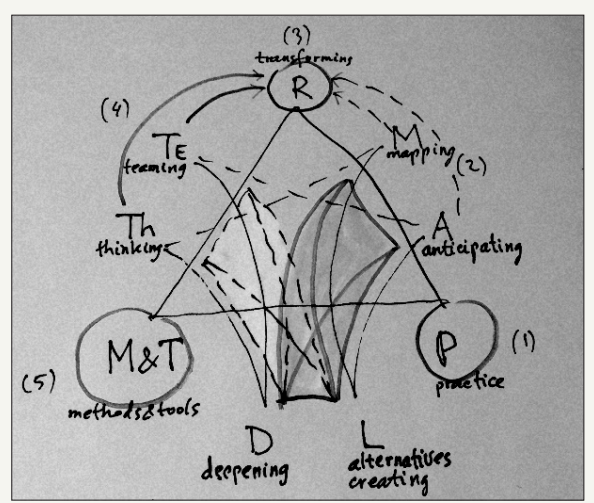

Figure 4: The $\mathrm{D}$ and $\mathrm{L}$ processes are common for the right and left quadrangles. The right is identified with the constructions that Shchedrovitsky exposes over the scheme of the thought activity, if the processes $\mathrm{D}, \mathrm{L}, \mathrm{A}$ and $\mathrm{M}$ are put in correspondence with $\mathrm{P}, \mathrm{O}, \mathrm{L}, \mathrm{S}$. The left rectangle corresponds to the space that the time grasps. Teaming (group self-determination) and Thinking (related to behavior and behavioral sciences) are to a certain extent processes of "symmetric" M and A (O and S). Symmetry we understand in the spirit of Vilczek [5].

\section{Discussion}

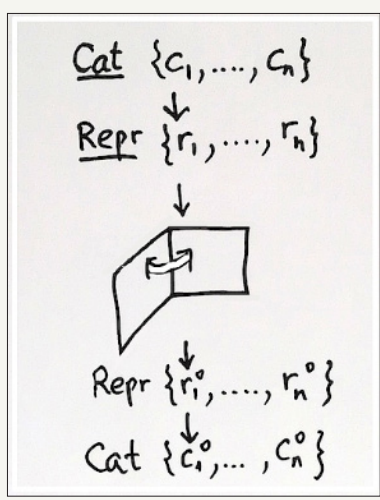

Figure 5: The expanded space of the game multilayer field.

A corporate philosophy, focused on professional community building, uses some value categories, which can be easily represented in the form of processes. You can try to apply the developed theory to the game with representatives of these categories Figure 5 . We would single out two stages of preparation for the game with "representatives of categories". First step. The categories we bring through representatives to a certain working field, where they enter into a categorical game, generating meanings that are then "directed" to categories, revealing some problematic nodes and points of development in them. What is the theme of the game? What reality (practical areas) do these categories reveal? How can the results of the game be "directed" to the original categorical fields? Or: what is the form of the representative's report on the results of his participation in the game?

At the second stage, representatives enter the game bridgehead and use methods and tools developed by the technologies of thinking and community building, to develop four processes (in the case of the first version of the theory) or six processes (in the case of the second version of the theory, the core theory).

Applying the core theory of cohesion to bioinformatics, to such aspects of it which tracks $1,7,8$, and 13 are represented. Suppose that these tracks may be describe in some categories. We define carriers of these categories and involve them into game where the processes leading to cohesion will imposed on the categories and their constellations. The categories may be developed as processes of standardization, attribution, technologizing, simulation, modelling, verification, validation, falsification, design, projecting, goal-putting, linearization, identification and estimation of effect. These processes interact each other forming knowledge on situation in bioinformatics, system biology, nanotechnology and other fields; they interact also with processes of problematization, objectivation, localization and schematization. Output of the multilayered fusion and design new approaches to organization, cooperation and collaboration the representatives of categories attain new prospects in their work on the categorial development, and, respectively, the content of the tracks' horizons.

If we consider the complexity that we discussed earlier regarding the construction of OSLP spaces in conditions of incomplete information, depicting those 14 intermediate cases, the game with an orientation to organizing and managing the processes of thought activity becomes extremely difficult. This complexity provides mental redundancy, so that we can extract the original categories from their historical niches and consider them in a new way, making different compositions and arrangements. The difficulty also arises on the way back, as the results of the game are implemented in the initial practical areas, as well as in understanding the process of transformation (change, modernization).

\section{References}

1. Forsyth DR (2010) Components of cohesion. Group Dynamics ( $5^{\text {th }}$ edn), Wadsworth: Cengage Learning, pp. 118-122.

2. Coherence and Chaos in our uncommon futures - visions. means. actions (1994) Selections from the XIII World Conference of the World Futures Studies Federation. In: Mika M, Sohaila IU, Rick S (Eds.), Turku, Finland.

3. Knyaginin VN (2015) Started another school of thinking technology in Jurmala. The theme for 2015 is schematization.

4. Saakov VV (2008) Positioned structure scheme mysledeyatelnosti i zadachi upravleniya. 
5. Wilczek F (2018) Tonkaya fizika. Massa fir i obyedineniye vsemirnykh sil.

6. Petr Shchedrovitskiy (2008) Obrazovaniye pered litsom novoy promyshlennoy revolyutsii (Tomsk) 7 noyab. 2016 g. // Lektsii PG Shchedrovitskogo.

7. Nekommercheskiy nauchnyy fond «Institut razvitiya imeni GP Shchedrovitskogo» [Nonprofit Scientific Fund 'Institute for development by name of Georgy Shchedrovitsky'].

8. Shchedrovitsky PG (2006) Ya vyros v arhive MMK [I grew in Archive of
Moscow methodology circle /Shchedrovitsky; Edito MS Khromchenko, Moscow, 'Institure of development by name of Georgy Shchedrovitsky' Nonprofit scientific fund p. 173.

9. Korolev P, Daradkeh Y, Aristova S (2017) Connecting Known and Unknown. The processes with uncertainty: How to approach and control? A Forty-Five-Cycle Universe Picture Design. LAP Lambert Academic Publishing p.97.

10. Wilczek F, Krasota F (2015) Postigaya ustroystvo prirody (A Beautiful Question. Finding Nature's Deep Design). Allen lane 2015. rus. per: Alpina Pablisher.

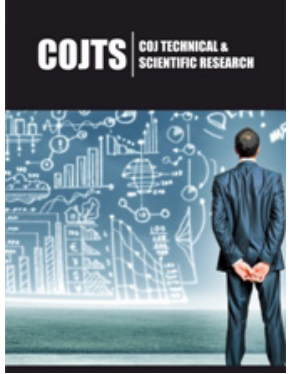

COJ Technical \& Scientific Research

\section{Benefits of Publishing with us}

- High-level peer review and editorial services

- Freely accessible online immediately upon publication

- Authors retain the copyright to their work

- Licensing it under a Creative Commons license

- Visibility through different online platforms 